\title{
Magnetic Properties of Well-Aligned ZnO Nanorod Arrays Grown by a Simple Hydrothermal Reaction
}

\author{
Jiangni Yun, Rui Qu, Zhiyong Zhang, and Jun Li \\ School of Information Science and Technology, Northwest University, Xian 710127, China \\ Correspondence should be addressed to Jiangni Yun; niniyun@nwu.edu.cn
}

Received 8 November 2013; Revised 23 January 2014; Accepted 31 January 2014; Published 29 April 2014

Academic Editor: Xuan Luo

Copyright (C) 2014 Jiangni Yun et al. This is an open access article distributed under the Creative Commons Attribution License, which permits unrestricted use, distribution, and reproduction in any medium, provided the original work is properly cited.

\begin{abstract}
Well-aligned $\mathrm{ZnO}$ nanorod arrays with room temperature ferromagnetism were prepared on glass substrate through hydrothermal method. The as-prepared nanorod arrays were characterized by X-ray diffraction (XRD), scanning electron microscopy (SEM), energy dispersive spectroscopy (EDS), photoluminescence (PL) spectrum, and magnetization measurements. The XRD and SEM results indicated that the $\mathrm{ZnO}$ nanorods are with the wurtzite structure and exhibit preferential (002) orientation with $c$-axis perpendicular to the substrate surface. The PL results suggested that the possible defect in the as-prepared $\mathrm{ZnO}$ nanorod arrays might be $\mathrm{V}_{\mathrm{Zn}}, \mathrm{O}_{\mathrm{i}}$, or $\mathrm{O}_{\mathrm{Zn}}$. The first-principles calculations reveal that the room temperature ferromagnetism may result from the $\mathrm{V}_{\mathrm{Zn}}$ defects present in the $\mathrm{ZnO}$ nanorod and the hybridization of the $\mathrm{Zn} 3 \mathrm{~d}$ states with $\mathrm{O} 2 \mathrm{p}$ states is responsible for the half-metallic ferromagnetism in $\mathrm{ZnO}$ nanorod.
\end{abstract}

\section{Introduction}

Recently, one-dimensional (1D) $\mathrm{ZnO}$ nanorods have attracted great interest due to their tunable magnetic and optoelectronic properties [1-8]. Particularly, for the potential applications in the spin electronics, the investigation to grow well-aligned $\mathrm{ZnO}$ nanorod arrays with room temperature ferromagnetism has been an urgent task because it is a key process toward realizing nanoscale devices [9-11]. Synthesis methods, such as physical vapor deposition [12], chemical vapor deposition [13], and pulsed laser deposition [14], have been extensively used to obtain $1 \mathrm{D}$ well-aligned $\mathrm{ZnO}$ nanorod arrays. However, these vapor-phase processes fabrication techniques need vacuum condition, high energy consumption, sophisticated equipment, and rigid experimental conditions. Compared with the vapor-phase processes, the hydrothermal process is a low cost and environmentally friendly method, which is highly welcomed by numerous researchers [15-18].

In this study, well-aligned, single crystalline $\mathrm{ZnO}$ nanorod arrays with room temperature ferromagnetism and high packing density were achieved via a simple hydrothermal process. A possible origin of the ferromagnetism in the prepared $\mathrm{ZnO}$ nanorod arrays related to the intrinsic defect is proposed.

\section{Experimental Details}

The procedure of the $\mathrm{ZnO}$ nanorod arrays prepared under hydrothermal condition consists of two steps: (a) preparation of $\mathrm{ZnO}$ seed-layer and (b) growth of $\mathrm{ZnO}$ nanorod arrays. In the first step, a layer of $\mathrm{ZnO}$ seed crystal was deposited on the glass substrate via sol-gel method. In detail, equal molar $\mathrm{Zn}\left(\mathrm{CH}_{3} \mathrm{COO}\right)_{2}-2 \mathrm{H}_{2} \mathrm{O}$ and glycolic amide $(0.35 \mathrm{~mol} / \mathrm{L})$ were solved in ethanol with stirring at $60^{\circ} \mathrm{C}$ for $12 \mathrm{~h}$ to yield a homogeneous solution. Subsequently, the precursor solution was dropped on the glass substrate, spinning at $3000 \mathrm{r} / \mathrm{min}$ for $30 \mathrm{~s}$. Then the substrate was preheated in air at $80^{\circ} \mathrm{C}$ for $10 \mathrm{~min}$. After that, the substrates were annealed at $500^{\circ} \mathrm{C}$ for $90 \mathrm{~min}$ in air to obtain a dense and transparent $\mathrm{ZnO}$ seed layer on the glass substrate by using an electronic furnace. In the second step, the glass substrate with a layer of $\mathrm{ZnO}$ seed crystal was placed into one autoclave filled with the precursor solutions of $\mathrm{Zn}\left(\mathrm{CH}_{3} \mathrm{COO}\right)_{2}-2 \mathrm{H}_{2} \mathrm{O}(0.04 \mathrm{M})$ and 


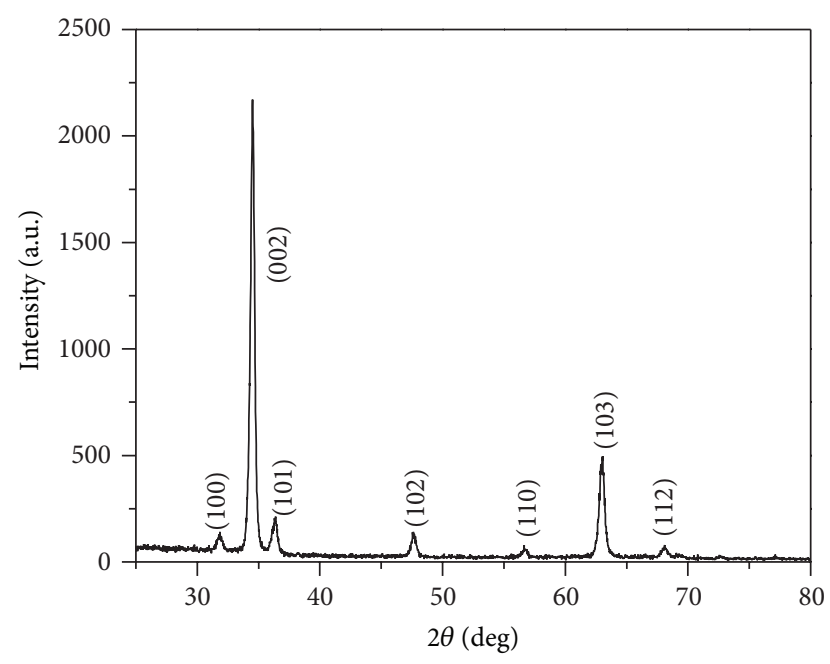

FIGURE 1: XRD pattern of the as-prepared $\mathrm{ZnO}$ nanorod arrays.

$\mathrm{NaOH}(0.08 \mathrm{M})$. After the autoclave is sealed safely, it is put into a bake oven at $120^{\circ} \mathrm{C}$ for $90 \mathrm{~min}$. Finally, the glass substrate with white deposit is purged in deionized water for several times.

The obtained products are characterized by using $\mathrm{X}$ ray diffraction (XRD, D/Max2550VB+/PC, Rigaku, Japan), scanning electron microscope (SEM, JSM-6390A, JEOL, Japan), photoluminescence spectrum (PL, FluoroMax-4p, HORIBA Jobin Yvon, USA), and a superconducting quantum interference device (MPMS-XL-7, Quantum Design, USA).

\section{Results and Discussion}

Figure 1 shows XRD pattern of the as-prepared sample. It is observed that all of the diffraction peaks can be well indexed to a wurtzite structure of $\mathrm{ZnO}$. The strong and narrow diffraction peaks indicate that the material has a good crystallinity. In particular, the as-prepared sample exhibits preferential $\left(\begin{array}{lll}0 & 0 & 2\end{array}\right)$ orientation with $c$-axis perpendicular to the substrate surface.

Figures 2(a) and 2(b) depict the SEM images of the prepared $\mathrm{ZnO}$ nanorod arrays. The low-magnification SEM image in Figure 2(a) demonstrates that the nanorod array is uniform and densely packed. From the high-magnification image in Figure 2(b), it can be seen that the prepared $\mathrm{ZnO}$ nanorod array exhibits typical wurtzite structure and preferential $\left(\begin{array}{lll}0 & 0 & 2\end{array}\right)$ orientation with $c$-axis perpendicular to the substrate surface, which is reflected by the XRD pattern shown in Figure 1. Furthermore, energy dispersive spectroscopy (EDS) result indicates that the as-prepared $\mathrm{ZnO}$ nanorod array is only composed of $\mathrm{Zn}$ and $\mathrm{O}$, and the atomic ratio of $\mathrm{Zn}$ and $\mathrm{O}$ is about $48.24: 51.76$. This suggests that the as-prepared nanorod arrays are nonstoichiometric and some defects may exist in the as-prepared nanorod arrays.

Figure 3 shows the room temperature PL spectra of the as-prepared $\mathrm{ZnO}$ nanorod arrays. A strong UV emission peak at $373 \mathrm{~nm}$ and three relatively weak and broad visible emissions centered at 425,511 , and $590 \mathrm{~nm}$, respectively, can

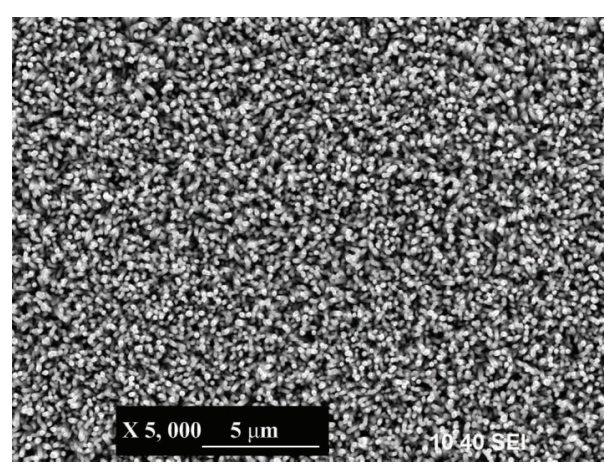

(a)

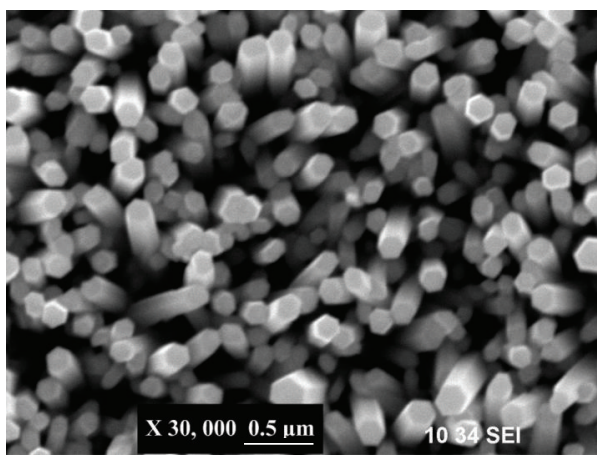

(b)

FIGURE 2: SEM images of $\mathrm{ZnO}$ nanorod arrays. (a) Large-scale and low magnification and (b) high magnification.

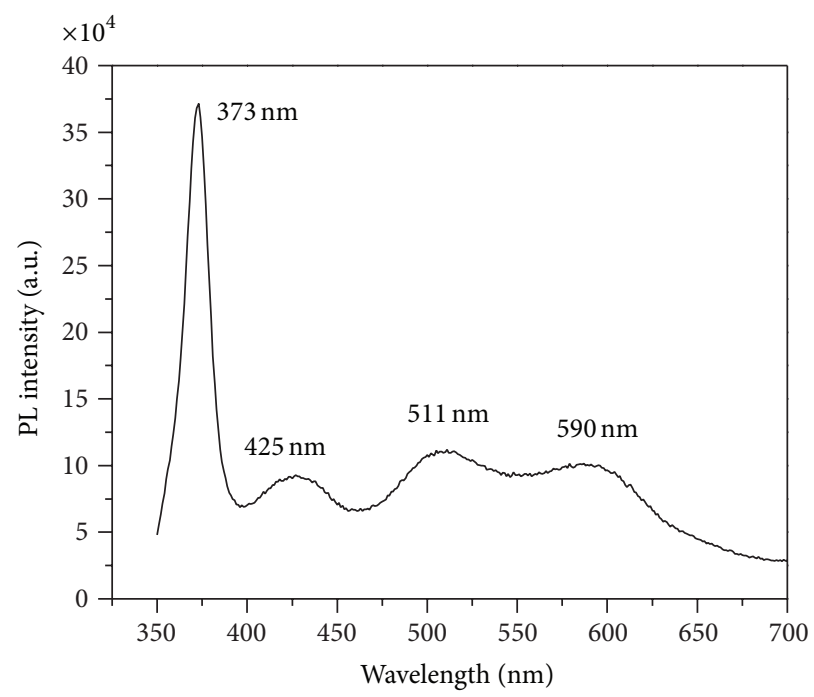

FIGURE 3: Room temperature PL spectra of the $\mathrm{ZnO}$ nanorod arrays.

be observed. The UV emission band is usually attributed to the near-band edge emission of the wide band gap of $\mathrm{ZnO}$ due to the annihilation of excitons $[8,19-21]$. The visible emission is the most commonly observed and is often attributed to the defect emission [22-27]. It is known that different defects may cause different electronic structures, which will be reflected on the corresponding optical properties observed in experiments. On the other hand, the electronic structure 


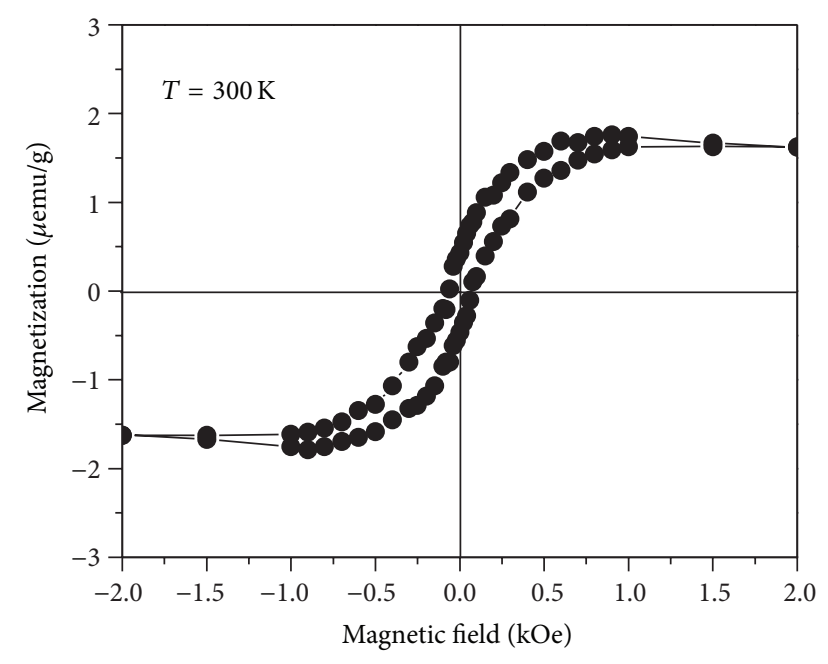

FIGURE 4: Magnetization hysteresis loops of $\mathrm{ZnO}$ nanorod arrays at $300 \mathrm{~K}$.

of the defects can be predicted unambiguously from density functional calculations. Hence, combining the experimental observations with theoretical results may identify different defects such as oxygen vacancy $\left(\mathrm{V}_{\mathrm{O}}\right)$, antisite oxygen $\left(\mathrm{O}_{\mathrm{Zn}}\right)$, zinc vacancy $\left(\mathrm{V}_{\mathrm{Zn}}\right)$, zinc interstitial $\left(\mathrm{Zn}_{\mathrm{i}}\right)$, and oxygen interstitial $\left(\mathrm{O}_{\mathrm{i}}\right)$ in $\mathrm{ZnO}$. Theoretically, $\mathrm{Xu}$ et al. and Sun et al. $[26,27]$ calculated the electronic structure of native point defects in $\mathrm{ZnO}$. Based on their results, the energy interval between the bottom of the conduction band (CB) and $\mathrm{V}_{\mathrm{Zn}}$ level $(3.06 \mathrm{eV})$ is approximately consistent with the energy of the blue-purple emission $(425 \mathrm{~nm}, 2.92 \mathrm{eV})$ observed in our experiment. The energy interval from the bottom of the $\mathrm{CB}$ to the $\mathrm{O}_{\mathrm{Zn}}$ level $(2.38 \mathrm{eV})$ is consistent with the energy of the green emission $(511 \mathrm{~nm}, 2.43 \mathrm{eV})$. The energy interval between the bottom of the $\mathrm{CB}$ and $\mathrm{O}_{\mathrm{i}}$ level $(2.28 \mathrm{eV})$ approximately conforms to the yellow emission $(590 \mathrm{~nm}$, $2.10 \mathrm{eV}$ ). By analysis of the experimental phenomena and the calculation of the defect levels in $\mathrm{ZnO}$, we suggest that the blue emission centered at $425 \mathrm{~nm}$ is attributed to $V_{Z n}[26,27]$, the green emission centered at $511 \mathrm{~nm}$ originates from $\mathrm{O}_{\mathrm{Zn}}$ $[26,27]$, and the yellow emission centered at $590 \mathrm{~nm}$ is related to $\mathrm{O}_{\mathrm{i}}$ [26]. Therefore the PL results reveal that the possible defect in the as-prepared $\mathrm{ZnO}$ nanorod arrays might be $\mathrm{V}_{\mathrm{Zn}}$, $\mathrm{O}_{\mathrm{i}}$, or $\mathrm{O}_{\mathrm{Zn}}$.

Figure 4 shows the magnetization as a function of the applied field at $300 \mathrm{~K}$ for the as-prepared $\mathrm{ZnO}$ nanorod arrays. The diamagnetic contribution from the glass substrate has been subtracted from the raw data. It is interesting that the $\mathrm{ZnO}$ nanorod arrays exhibit room temperature ferromagnetism. The saturation magnetization $\mathrm{M}_{s}$ and remanent magnetization $\mathrm{M}_{\mathrm{r}}$ are about $1.7 \times 10^{-3}$ and $4.33 \times$ $10^{-4} \mathrm{emu} / \mathrm{g}$, respectively. The coercivity $\mathrm{H}_{\mathrm{c}}$ is about $60 \mathrm{Oe}$. As we know, neither doping nor evidence of secondary phase exit in the as-prepared $\mathrm{ZnO}$ nanorod arrays; the observed room temperature ferromagnetism in the as-prepared $\mathrm{ZnO}$ nanorod arrays probably results from the intrinsic defect.

In order to provide more insight into this issue, we employed first-principles calculation [28] on the electronic structure and magnetic properties for the $\mathrm{ZnO}$ nanorod.
Since the PL study results reveal that the possible defect in the as-prepared $\mathrm{ZnO}$ nanorod arrays might be $\mathrm{V}_{\mathrm{Zn}}, \mathrm{O}_{\mathrm{i}}$, or $\mathrm{O}_{\mathrm{Zn}}$, thus, in the present calculations, the $\mathrm{ZnO}$ nanorods with $\mathrm{V}_{\mathrm{Zn}}, \mathrm{O}_{\mathrm{i}}$, or $\mathrm{O}_{\mathrm{Zn}}$ defect are investigated. The wurtzite supercell containing 96 atoms is used for calculation. For the $\mathrm{ZnO}$ nanorod with $\mathrm{V}_{\mathrm{Zn}}$ or $\mathrm{O}_{\mathrm{Zn}}$ defect, there are three inequivalent defect positions, which are denoted as $\mathrm{V}_{\mathrm{Zn} 1}-\mathrm{V}_{\mathrm{Zn} 3}$ and $\mathrm{O}_{\mathrm{Zn} 1}-$ $\mathrm{O}_{\mathrm{Zn} 3}$, as shown in Figures 5(a) and 5(b). However, there are two inequivalent $\mathrm{O}_{\mathrm{i}}$ defect positions, which are denoted as $\mathrm{O}_{\mathrm{i} 1}$ and $\mathrm{O}_{\mathrm{i} 2}$ as shown in Figure 5(c). The formation energy of $\mathrm{V}_{\mathrm{Zn}}$ at $\mathrm{V}_{\mathrm{Zn} 2}$ site is about 0.12 and $0.38 \mathrm{eV}$ smaller than that at the $\mathrm{V}_{\mathrm{Zn} 1}$ and $\mathrm{V}_{\mathrm{Zn} 3}$ sites, respectively, and, thus, $\mathrm{V}_{\mathrm{Zn} 2}$ is the most stable site for $\mathrm{V}_{\mathrm{Zn}}$ defect. Similar to $\mathrm{V}_{\mathrm{Zn}}, \mathrm{O}_{\mathrm{Zn}}$ also prefers at the $\mathrm{O}_{\mathrm{Zn} 2}$ site. While for the $\mathrm{O}_{\mathrm{i}}$ defect, it prefers at the $\mathrm{O}_{\mathrm{i} 1}$ site. Therefore, the magnetic properties of $\mathrm{ZnO}$ nanorod with $\mathrm{V}_{\mathrm{Zn}}, \mathrm{O}_{\mathrm{Zn}}$, and $\mathrm{O}_{\mathrm{i}}$ are calculated based on the $\mathrm{V}_{\mathrm{Zn} 2}, \mathrm{O}_{\mathrm{Zn} 2}$, and $\mathrm{O}_{\mathrm{i} 1}$ geometries, respectively.

The calculated densities of states (DOSs) for the $\mathrm{ZnO}$ nanorod with $\mathrm{V}_{\mathrm{Zn}}, \mathrm{O}_{\mathrm{i}}$, or $\mathrm{O}_{\mathrm{Zn}}$ defect are shown in Figure 6 . It is clear that the spin-up and spin-down DOSs of pure $\mathrm{ZnO}$ nanorod are completely symmetrical, indicating that the pure $\mathrm{ZnO}$ nanorod is nonmagnetic. Similarly, the $\mathrm{ZnO}$ nanorod with $\mathrm{O}_{\mathrm{i}}$ or $\mathrm{O}_{\mathrm{Zn}}$ defect also exhibits nonmagnetic properties. As for the $\mathrm{ZnO}$ nanorod with $\mathrm{V}_{\mathrm{Zn}}$ defect, however, a strong spin splitting phenomenon is observed. The Fermi level passes through the band gap in the spin-down DOS and an energy gap of about $1.47 \mathrm{eV}$ exists in the spin-up DOS. This demonstrates that the $\mathrm{ZnO}$ nanorod with $\mathrm{V}_{\mathrm{Zn}}$ behaves as halfmetallic.

By analysis of the partial densities of states (PDOSs) in Figure 7, it can be found that the metallic spin-down DOS near the Fermi level is mainly composed of $\mathrm{Zn} 3 \mathrm{~d}$ and $\mathrm{O} 2 \mathrm{p}$ states. In particular, $\mathrm{O} 2 \mathrm{p}$ states make significant contribution to the magnetic moment. This suggests that the appearance of the half-metallic ferromagnetism in $\mathrm{ZnO}$ nanorod with $\mathrm{V}_{\mathrm{Zn}}$ originates from the hybridization of the $\mathrm{Zn} 3 \mathrm{~d}$ states with $\mathrm{O}$ $2 \mathrm{p}$ states.

\section{Conclusions}

In conclusion, $\mathrm{ZnO}$ nanorod arrays with room temperature ferromagnetism were prepared on glass substrate through hydrothermal method. The as-prepared sample shows preferential $\left(\begin{array}{lll}0 & 0 & 2\end{array}\right)$ orientation with $c$-axis perpendicular to the substrate surface. The room temperature PL measurements exhibit a prominent UV peak at about $373 \mathrm{~nm}$ which is attributed to the annihilation of excitons. Three relatively weak and broad visible emissions resulting from the defects can also be observed in the PL spectrum. By analysis of the calculated electronic structure of the $\mathrm{ZnO}$ nanorod with defects, we can get the conclusion that the $V_{\mathrm{Zn}}$ defects present in the $\mathrm{ZnO}$ nanorods are responsible for the room temperature ferromagnetism.

\section{Conflict of Interests}

The authors declare that there is no conflict of interests regarding the publication of this paper. 


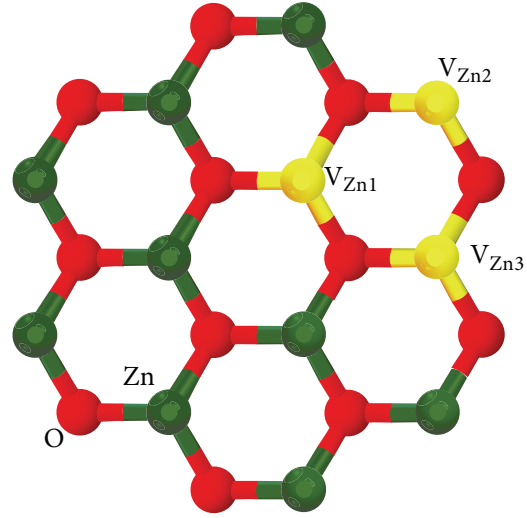

(a)

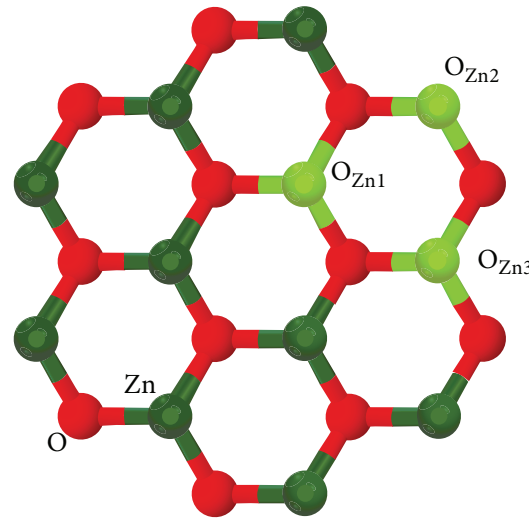

(b)

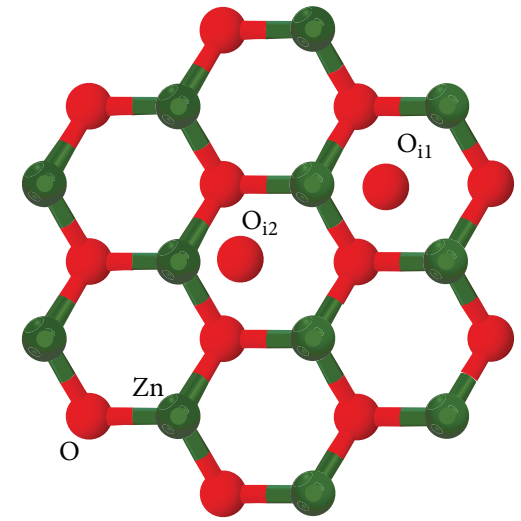

(c)

FIGURE 5: The structure of $\mathrm{ZnO}$ nanorods (a) with $\mathrm{V}_{\mathrm{Zn}}$, (b) with $\mathrm{O}_{\mathrm{i}}$, and (c) with $\mathrm{O}_{\mathrm{Zn}}$ defect.

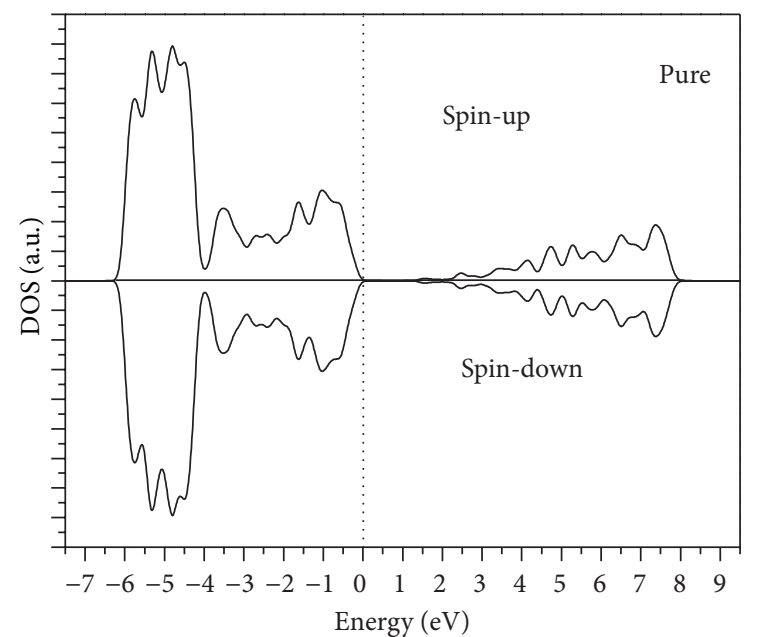

(a)

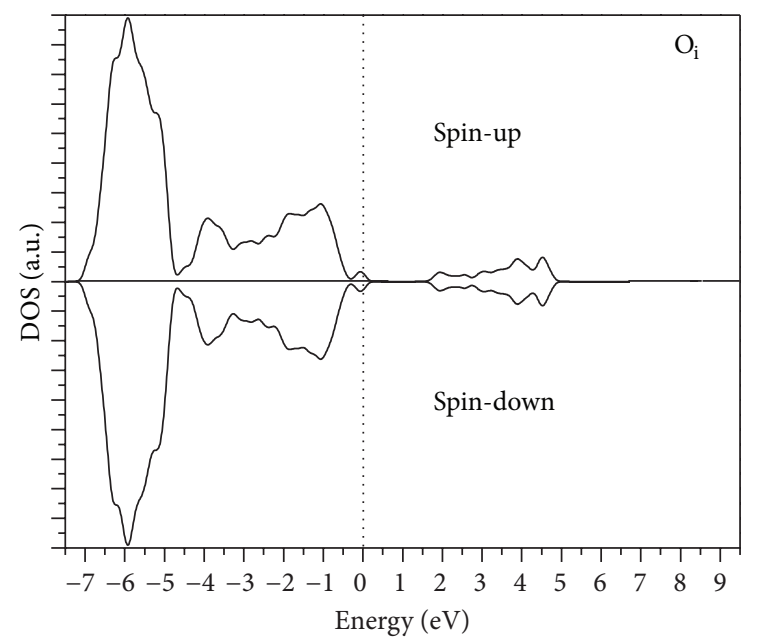

(c)

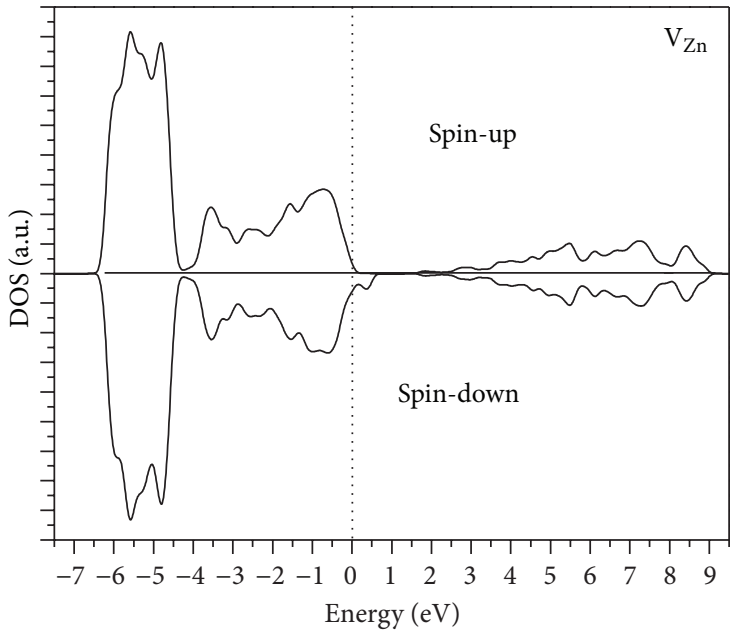

(b)

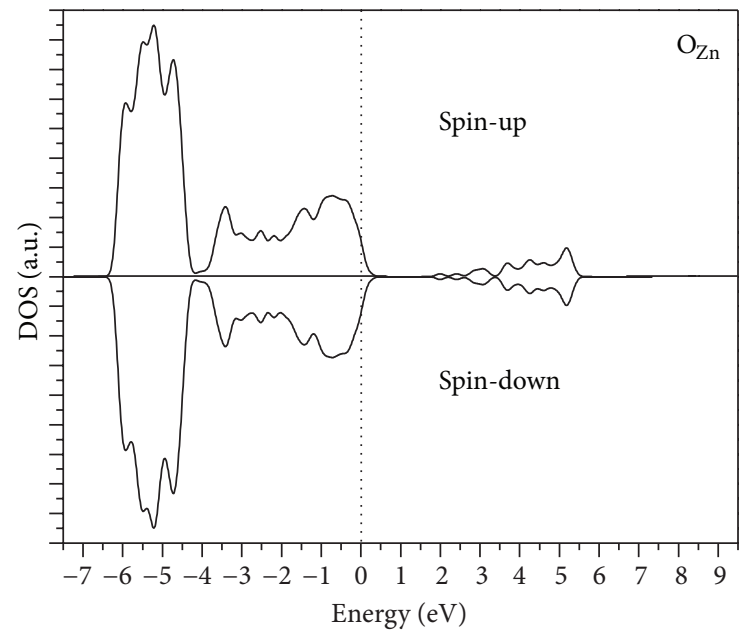

(d)

FIGURE 6: Calculated DOSs for ZnO nanorod. The Fermi level is set to zero on the energy scale, which will be adopted below unless otherwise stated. 


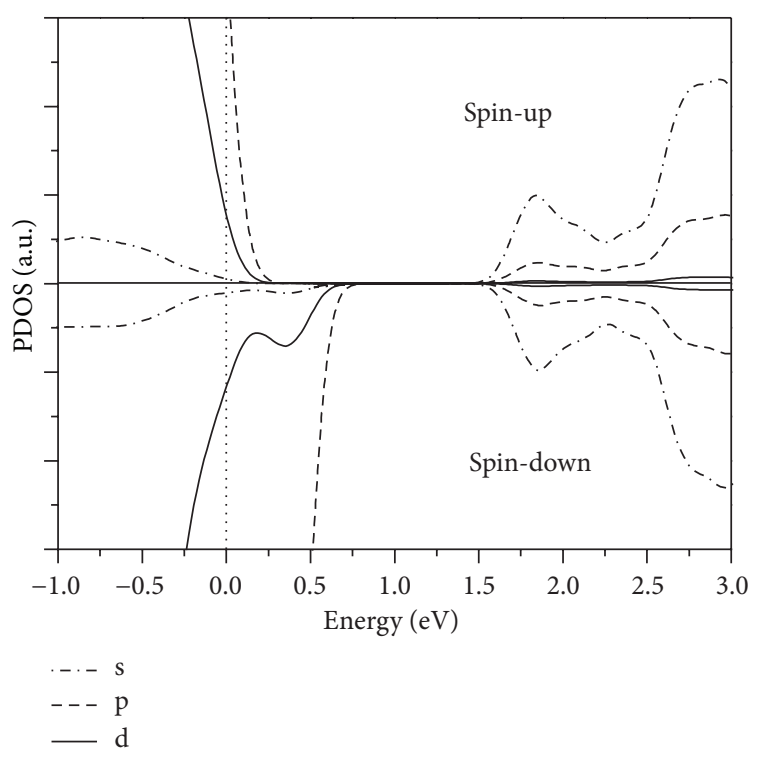

FIGURE 7: Calculated PDOS for $\mathrm{ZnO}$ nanorod with $\mathrm{V}_{\mathrm{Zn}}$ defect.

\section{Acknowledgments}

This work is supported by the Natural Science Basic Research Plan in Shaanxi Province of China (Program nos. 2011JQ8034 and 2013KJXX-24), the Open Foundation of Key Laboratory of Photoelectronic Technology of Shaanxi Province (Grant no. ZS11009), the Science Foundation of Northwest University (nos. 10NW08 and PR10069), and the NWU Graduate Innovation and Creativity Funds (09YZZ64). The authors are also thankful for the support of the Scientific Research Program funded by the Shaanxi Provincial Education Department (Program no. 11JK0831).

\section{References}

[1] W. Wu, G. Hu, S. Cui, Y. Zhou, and H. Wu, "Epitaxy of vertical $\mathrm{ZnO}$ nanorod arrays on highly (001)-oriented $\mathrm{ZnO}$ seed monolayer by a hydrothermal route," Crystal Growth and Design, vol. 8, no. 11, pp. 4014-4020, 2008.

[2] J. T. Chen, J. Wang, R. F. Zhuo et al., "The effect of Al doping on the morphology and optical property of $\mathrm{ZnO}$ nanostructures prepared by hydrothermal process," Applied Surface Science, vol. 255, no. 7, pp. 3959-3964, 2009.

[3] Z. Y. Wang, B. Huang, X. Qin et al., "Growth of high transmittance vertical aligned $\mathrm{ZnO}$ nanorod arrays with polyvinyl alcohol by hydrothermal method," Materials Letters, vol. 63, no. 1, pp. 130-132, 2009.

[4] T. G. You, J. Yan, Z. Zhang et al., "Fabrication and optical properties of needle-like $\mathrm{ZnO}$ array by a simple hydrothermal process," Materials Letters, vol. 66, no. 1, pp. 246-249, 2011.

[5] S. Ilican, "Effect of $\mathrm{Na}$ doping on the microstructures and optical properties of $\mathrm{ZnO}$ nanorods," Journal of Alloys and Compounds, vol. 553, pp. 225-232, 2013.

[6] M. Guo, P. Diao, and S. Cai, "Hydrothermal growth of wellaligned $\mathrm{ZnO}$ nanorod arrays: dependence of morphology and alignment ordering upon preparing conditions," Journal of Solid State Chemistry, vol. 178, no. 6, pp. 1864-1873, 2005.
[7] Z. Li, X. Huang, J. Liu, Y. Li, X. Ji, and G. Li, "Growth and comparison of different morphologic $\mathrm{ZnO}$ nanorod arrays by a simple aqueous solution route," Materials Letters, vol. 61, no. 22, pp. 4362-4365, 2007.

[8] M. H. Huang, S. Mao, H. Feick et al., "Room-temperature ultraviolet nanowire nanolasers," Science, vol. 292, no. 5523, pp. 1897-1899, 2001.

[9] Y. Lee, Y. Zhang, S. L. G. Ng, F. C. Kartawidjaja, and J. Wang, "Hydrothermal growth of vertical $\mathrm{ZnO}$ nanorods," Journal of the American Ceramic Society, vol. 92, no. 9, pp. 1940-1945, 2009.

[10] H. L. Yan, X. L. Zhong, J. B. Wang et al., "Cathodoluminescence and room temperature ferromagnetism of $\mathrm{Mn}$-doped $\mathrm{ZnO}$ nanorod arrays grown by chemical vapor deposition," Applied Physics Letters, vol. 90, no. 8, Article ID 082503, 2007.

[11] A. B. Djuriić, A. M. C. Ng, and X. Y. Chen, "ZnO nanostructures for optoelectronics: material properties and device applications," Progress in Quantum Electronics, vol. 34, no. 4, pp. 191-259, 2010.

[12] E. Oh, S.-H. Jung, K.-H. Lee, S.-H. Jeong, S. Yu, and S. J. Rhee, "Vertically aligned $\mathrm{Fe}$-doped $\mathrm{ZnO}$ nanorod arrays by ultrasonic irradiation and their photoluminescence properties," Materials Letters, vol. 62, no. 19, pp. 3456-3458, 2008.

[13] J. Wu, S. Liu, and M. Yang, "Room-temperature ferromagnetism in well-aligned $\mathrm{Zn}_{1-x} \mathrm{Co}_{x} \mathrm{O}$ nanorods," Applied Physics Letters, vol. 85, no. 6, pp. 1027-1029, 2004.

[14] J. J. Chen, M. H. Yu, W. L. Zhou, K. Sun, and L. M. Wang, "Room-temperature ferromagnetic Co-doped $\mathrm{ZnO}$ nanoneedle array prepared by pulsed laser deposition," Applied Physics Letters, vol. 87, no. 17, p. 173119, 2005.

[15] J. Xu, Y. P. Chen, D. Y. Chen, and J. N. Shen, "Hydrothermal synthesis and gas sensing characters of $\mathrm{ZnO}$ nanorods," Sensors and Actuators B: Chemical, vol. 113, no. 1, pp. 526-531, 2006.

[16] S. Kumar, Y. J. Kim, B. H. Koo et al., "Room temperature ferromagnetism in chemically synthesized $\mathrm{ZnO}$ rods," Materials Letters, vol. 63, no. 2, pp. 194-196, 2009.

[17] L. Z. Pei, H. S. Zhao, W. Tan et al., "Hydrothermal oxidization preparation of $\mathrm{ZnO}$ nanorods on zinc substrate," Physica E: Low-Dimensional Systems and Nanostructures, vol. 42, no. 5, pp. 1333-1337, 2010.

[18] A. Aravind, M. K. Jayaraj, M. Kumar, and R. Chandra, “Optical and magnetic properties of copper doped $\mathrm{ZnO}$ nanorods prepared by hydrothermal method," Journal of Materials Science: Materials in Electronics, vol. 24, no. 1, pp. 106-112, 2013.

[19] H. G. Kim, D. W. Hwang, and J. S. Lee, "An undoped, singlephase oxide photocatalyst working under visible light," Journal of the American Chemical Society, vol. 126, no. 29, pp. 8912-8913, 2004.

[20] R. Elilarassi and G. Chandrasekaran, "Structural, optical and magnetic properties of nanoparticles of $\mathrm{ZnO}: \mathrm{Ni}-\mathrm{DMS}$ prepared by sol-gel method," Materials Chemistry and Physics, vol. 123, no. 2-3, pp. 450-455, 2010.

[21] K. H. Tam, C. K. Cheung, Y. H. Leung et al., "Defects in $\mathrm{ZnO}$ Nanorods Prepared by a Hydrothermal Method," The Journal of Physical Chemistry B, vol. 110, no. 42, pp. 20865-20871, 2006.

[22] F. Ahmed, S. Kumar, N. Arshi, M. S. Anwar, B. H. Koo, and C. G. Lee, "Defect induced room temperature ferromagnetism in well-aligned $\mathrm{ZnO}$ nanorods grown on $\mathrm{Si}(100)$ substrate," Thin Solid Films, vol. 519, no. 23, pp. 8199-8202, 2011.

[23] Q. X. Zhao, P. Klason, and M. Willander, "Deep-level emissions influenced by $\mathrm{O}$ and $\mathrm{Zn}$ implantations in $\mathrm{ZnO}$," Applied Physics Letters, vol. 87, no. 21, p. 211912, 2005. 
[24] A. F. Kohan, G. Ceder, D. Morgan, and C. G. van de Walle, "First-principles study of native point defects in ZnO," Physical Review B-Condensed Matter and Materials Physics, vol. 61, no. 22, pp. 15019-15027, 2000.

[25] A. B. Djurišić and Y. H. Leung, "Optical properties of $\mathrm{ZnO}$ nanostructures," Small, vol. 2, no. 8-9, pp. 944-961, 2006.

[26] P. S. Xu, Y. M. Sun, C. S. Shi, F. Q. Xu, and H. B. Pan, "The electronic structure and spectral properties of $\mathrm{ZnO}$ and its defects," Nuclear Instruments and Methods in Physics Research B: Beam Interactions with Materials and Atoms, vol. 199, pp. 286290, 2003.

[27] Y. M. Sun, FP-LMTO study on the electronic structure of $\mathrm{ZnO}$ and its defects [Ph.D. dissertation], University of Science and Technology of China, 2000.

[28] M. D. Segall, P. J. D. Lindan, M. J. Probert et al., "First-principles simulation: ideas, illustrations and the CASTEP code," Journal of Physics Condensed Matter, vol. 14, no. 11, pp. 2717-2744, 2002. 

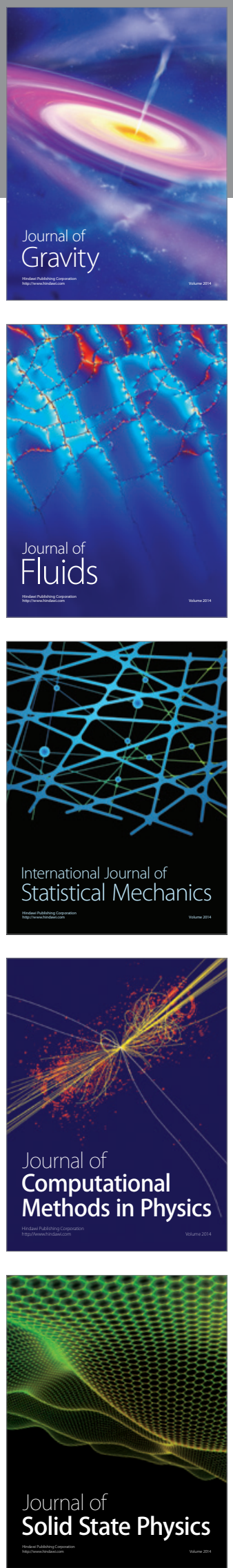

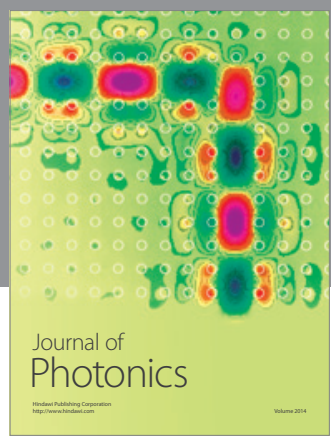

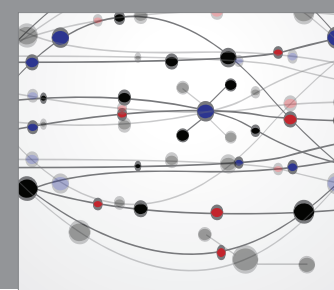

The Scientific World Journal

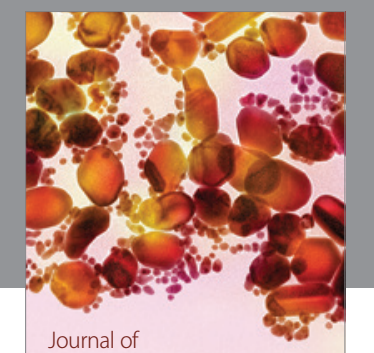

Soft Matter
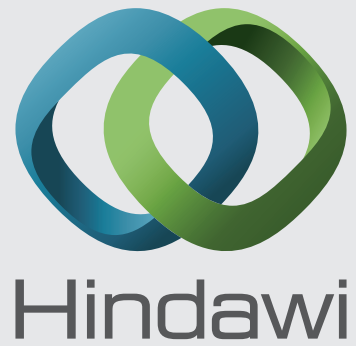

Submit your manuscripts at

http://www.hindawi.com
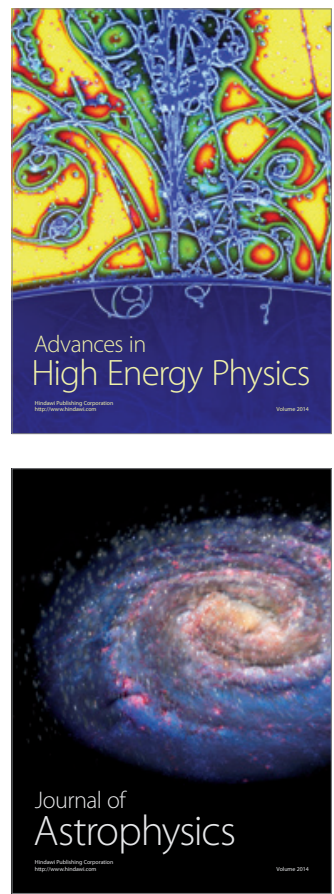
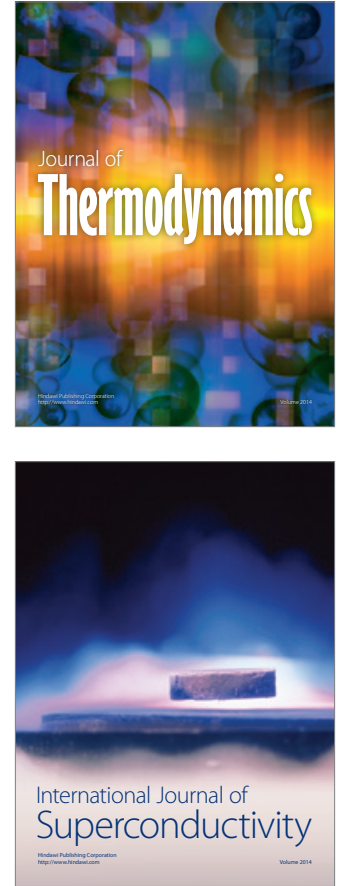
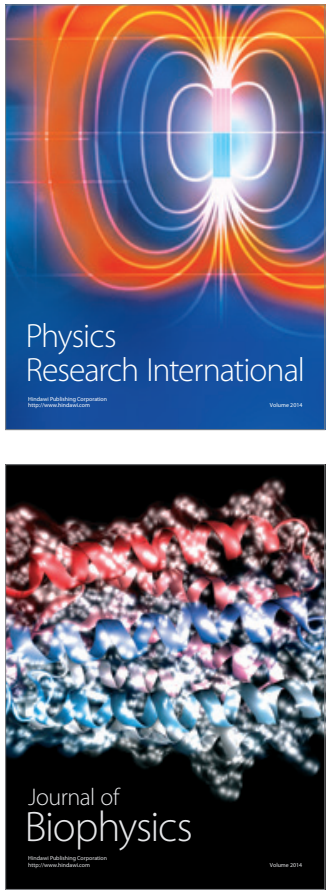
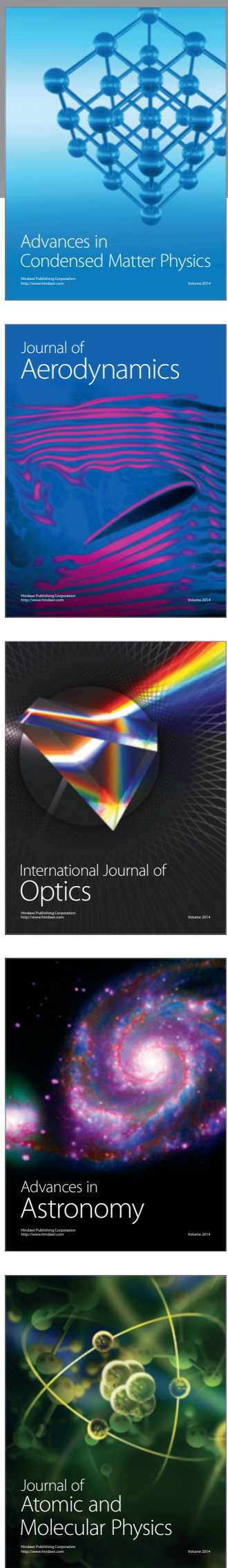